http://jmscr.igmpublication.org/home/ ISSN (e)-2347-176x ISSN (p) 2455-0450 crossref DOI: https://dx.doi.org/10.18535/jmscr/v8i2.86

\author{
Dournal Of Medical Science And Clinical Research \\ IGM Publication \\ An official Publication of IGM Publication
}

\title{
MRI Evaluation of Compressive Myelopathy
}

\section{Authors \\ Dr Satyendra Mohapatra ${ }^{1}$, Dr Braja Behari Panda ${ }^{2^{*}}$, Dr Savitri Bhagat ${ }^{3}$, Dr Amulya Kumar Panda ${ }^{4}$}

${ }^{1}$ PG Resident, Veer Surendra Sai Institute of Medical Sciences and Research (VIMSAR), Burla

${ }^{2}$ Associate Professor, Department of Radiodiagnosis, Veer Surendra Sai Institute of Medical Sciences and Research, Burla

${ }^{3}$ Professor and H.O.D., Department of Radiodiagnosis, Veer Surendra Sai Institute of Medical Sciences and

Research, Burla

${ }^{4}$ Senior Resident, Department of Radiodiagnosis, Veer Surendra Sai Institute of Medical Sciences and

Research, Burla

*Corresponding Author

Dr Braja Behari Panda

Abstract

Background: Compressive myelopathy is the term used to describe the spinal cord compression either from outside or within the cord. The role of MRI is to distinguish compressive from noncompressive cause of myelopathy.

Material \& Method: A cross sectional study of 60 patients with clinical history of compressive myelopathy are evaluated for various causes by 1.5 Tesla MRI scanner.

Result: Out of 60 cases of compressive myelopathy various different causes are trauma (26), Infection (14), Primary Neoplasm (10), Secondary Neoplasm (10).

Conclusion: MRI is very definitive, Sensitive, Accurate, Noninvasive, Radiation free modality for evaluation of compressive myelopathy.

Keyword: MRI, Compressive myelopathy, Primary Neoplasm, Secondary Neoplasm.

\section{Introduction}

Compressive myelopathy is the term used to describe the spinal cord compression either from outside or within the cord itself. Compression may be due to trauma, displaced vertebrae, epidural abscess, epidural hemorrhage, intradural and extradural neoplasm.

Spinal cord injury is the major cause of quadriplegia and disability. Plain Radiograph has a low sensitivity for identifying traumatic spinal lesion. In patients who have negative plain film for spinal injury but high clinical suspicion of spinal injury should undergo MR for a more definitive evaluation of spine. MRI is a definite modality for assessing soft tissue injuries.

In case of suspected cord compression due to neoplasm, MRI serves as an excellent method for imaging tumour involving spinal column, canal and cord. Of all the areas of spinal pathology, It may be in the field of spinal tumour that MRI has had most impact.

Spinal tumour are categorized as extradural, intradural extra medullary, intra medullary. 
Secondary tumour may arise from lungs carcinoma, breast carcinoma, lymphoma and renal cell carcinoma, maximum lesion are extradural in location.

Infectious etiology of spinal compression are mainly due to tubercular. Maximum infectious lesions are extra dural.

Many spinal cord diseases are reversible if recognized and treated in early stage.

\section{Material \& Method}

- The study was conducted in VIMSAR, Burla. We included 60 patients of both sex.

- The study was conducted from September 2017 to August 2019, 2 years.

- All the patients underwent MRI evaluation.

\section{Inclusion Criteria}

- All age group> $10 \mathrm{yr}$, both sex, all cases of compressive myelopathy.

\section{Exclusion Criteria}

- Cases of non-compressive myelopathy

- Degenerative disc herniation.

MRI evaluation is performed by GE 1.5 TESLA Electromagnet machine.

Whenever possible patients were followed up for histopathological diagnosis in case of neoplasm and outcome in case of spinal trauma

\section{Observation}

All the patients with compressive myelopathy were subjected to MRI evaluation.

- MRI evaluate various cause of compressive myelopathy

- MRI used to classify the lesion based on location in to extra dural and intra dural

- MRI also evaluate age and sex distribution of various causes of compressive myelopathy

Table 1: Causes of Compressive myelopathy

\begin{tabular}{|l|c|c|}
\hline MR diagnosis & Number of patients(n=60) & \% \\
\hline Traumatic Myelopathy & 26 & 43.3 \\
\hline Infection/TB & 14 & 23.3 \\
\hline Primary neoplasm & 10 & 16.7 \\
\hline Secondary Neoplasm/Metastases & 10 & 16.7 \\
\hline
\end{tabular}

Most common cause for compressive myelopathy in our study was spinal trauma (43.3\%) followed by spinal infection $(23.3 \%)$.

Table 2: Level of Spinal Injury

\begin{tabular}{|l|c|c|}
\hline Level of lesion & Number of patients(n=26) & \% \\
\hline C: Cervical & 12 & 46.2 \\
\hline T: Thoracic & 14 & 53.8 \\
\hline LT: Lower Thoracic & 12 & 46.2 \\
\hline UT: UpperThoracic & 2 & 7.7 \\
\hline TL: Thraco - Lumbar & 0 & 0.0 \\
\hline L: Lumbar & 4 & 15.4 \\
\hline
\end{tabular}

Thoracic is the most common site of spinal injury.

Table 3: Infectious Causes of Compressive Myelopathy

\begin{tabular}{|l|c|}
\hline Infection & No. of Patients (Total 14) \\
\hline Tubercular & 12 \\
\hline Pyogenic Epidural Abscess & 1 \\
\hline Hypertrophic Pachymeningitis & 1 \\
\hline
\end{tabular}

Tuberculosis is the most common infectious cause of compressive myelopathy. 
Table 4: Age, Gender \& Compartmental Distribution of Various Causative factors according to the MRI Finding

\begin{tabular}{|c|c|c|c|c|c|}
\hline \multirow[b]{2}{*}{ Variables } & \multicolumn{4}{|c|}{ MR diagnosis } & \multirow[t]{2}{*}{ P value } \\
\hline & $\underset{(n=26)}{\text { Traumatic }}$ & $\begin{array}{c}\text { Infection } \\
(\mathbf{n}=14)\end{array}$ & $\begin{array}{c}\text { Primary } \\
\text { Neoplasm } \\
(\mathbf{n}=10)\end{array}$ & $\begin{array}{c}\text { Secondary } \\
\text { /Neoplasm } \\
\text { metastases } \\
(\mathbf{n}=10)\end{array}$ & \\
\hline \multicolumn{6}{|l|}{\begin{tabular}{|l} 
Age in Years \\
\end{tabular}} \\
\hline - $11-20$ & $\begin{array}{c}2 \\
(7.0 \%)\end{array}$ & $2(14.2 \%)$ & $0(0 \%)$ & $0(0 \%)$ & \multirow{5}{*}{0.462} \\
\hline - $21-30$ & $6(23.0 \%)$ & $2(14.2 \%)$ & $0(0 \%)$ & $0(0 \%)$ & \\
\hline - $\quad 31-40$ & $6(23.0 \%)$ & $2(14.2 \%)$ & $2(20 \%)$ & $0(0 \%)$ & \\
\hline - $41-50$ & $4(15.3 \%)$ & $2(14.2 \%)$ & $4(40 \%)$ & $2(20 \%)$ & \\
\hline - $\quad>50$ & $8(30.8 \%)$ & $6(42.9 \%)$ & $4(40 \%)$ & $8(80 \%)$ & \\
\hline \multicolumn{6}{|l|}{ Gender } \\
\hline - Male & $22(84.6 \%)$ & $6(42.9 \%)$ & $4(40 \%)$ & $4(40 \%)$ & \multirow[b]{2}{*}{0.110} \\
\hline - Female & $4(15.4 \%)$ & $8(57.1 \%)$ & $6(60 \%)$ & $6(60 \%)$ & \\
\hline \multicolumn{6}{|l|}{ Compartment } \\
\hline - Extradural & $26(100 \%)$ & $14(100 \%)$ & $0(0 \%)$ & $10(100 \%)$ & \multirow{2}{*}{$<0.001 * *$} \\
\hline - Intradural & $0(0 \%)$ & $0(0 \%)$ & $10(100 \%)$ & $0(0 \%)$ & \\
\hline
\end{tabular}

Table 5: Characterisation of Traumatic Spinal Injuries by MRI

\begin{tabular}{|l|c|c|}
\hline \multicolumn{1}{|c|}{ MRI finding } & No. of patients $(\mathbf{n = 2 6})$ & \% \\
\hline 1.Stable fractures & 12 & 46.2 \\
\hline 2.Unstable fractures & 14 & 53.8 \\
\hline 3.Posterior elements fracture & 14 & 53.8 \\
\hline 4.Ligamentous injury & 14 & 53.8 \\
\hline 5.Cord changes & 24 & 92.3 \\
\hline 6.Epidural hematoma/ soft tissue component & 12 & 46.2 \\
\hline 7.Pre and paravertebral collection & 12 & 46.2 \\
\hline
\end{tabular}

Table 6: Primary Tumour Classification

\begin{tabular}{|l|c|}
\hline Primary neoplasms & No. of patients \\
\hline Neurofibroma & 04 \\
\hline Meningioma & 06 \\
\hline Total & $\mathbf{1 0}$ \\
\hline
\end{tabular}

Meningioma is the most common cause of primary tumour causing compressive myelopathy.

Table 7: Location of Primary Tumour

\begin{tabular}{|l|c|c|c|}
\hline Diagnosis & Cervical & Thoracic & Lumbar \\
\hline Meningioma & 0 & 4 & 2 \\
\hline Neurofibroma & 2 & 2 & 0 \\
\hline
\end{tabular}

Meningioma are more common in thoracic region where as neurofibroma are common in thoracic \& cervical region.

Table 8: Site of Metastasis

\begin{tabular}{|l|c|c|}
\hline $\begin{array}{l}\text { Levels of lesions in } \\
\text { Secondary neoplasm/metastases }\end{array}$ & $\begin{array}{c}\text { Number of patients } \\
(\mathbf{n}=\mathbf{1 0})\end{array}$ & $\boldsymbol{\%}$ \\
\hline Cervical & 2 & 20.0 \\
\hline Thoracic & 8 & 80.0 \\
\hline Upper & 4 & 40.0 \\
\hline Lower & 4 & 40.0 \\
\hline Thoraco lumbar $\left(\mathrm{T}_{12}-\mathrm{L}_{1}\right)$ & 0 & 0.0 \\
\hline Lumbar & 2 & 20.0 \\
\hline
\end{tabular}

Thoracic region is the most common site of metastasis. 


\section{JMSCR VoI||08||Issue||02||Page 496-500||February}

Table 9: Location of the Pathology

\begin{tabular}{|l|c|c|}
\hline Compartment & Number of patients & \% \\
\hline Extradural & 50 & 83.3 \\
\hline Intradural - Extramedullary & 10 & 16.7 \\
\hline Total & 60 & 100.0 \\
\hline
\end{tabular}

Extradural compressive lesions (83.3\%) are the most common cause for compressive myelopathy.

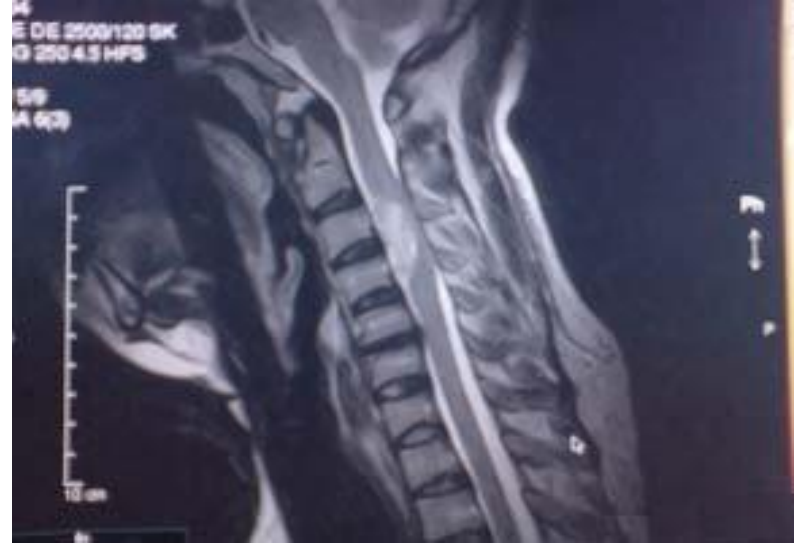

Image 1: $\mathrm{T}_{2} \mathrm{Sag}$ Intradural Extramedullary

Neurofibroma

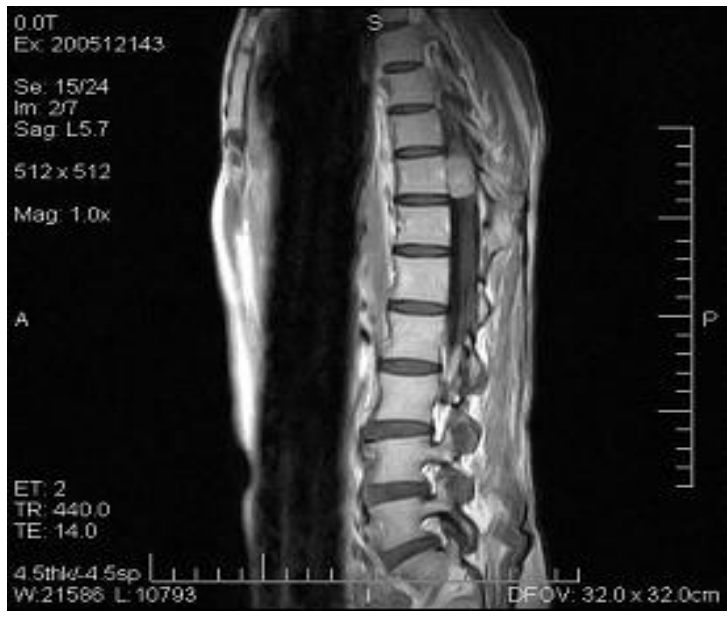

Image 2: Post Contrast sag Meningioma

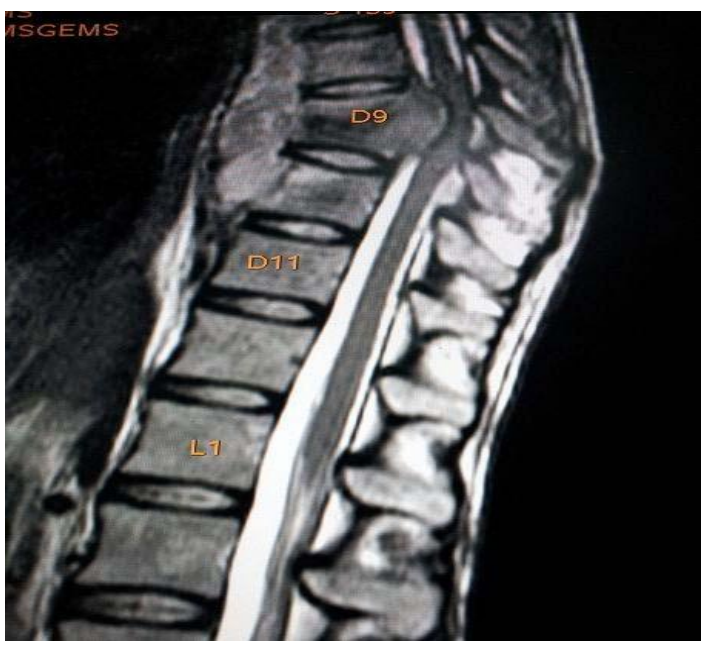

Image 3: $T_{2}$ Sag Tuberculosis of Spine with Cold Abscess

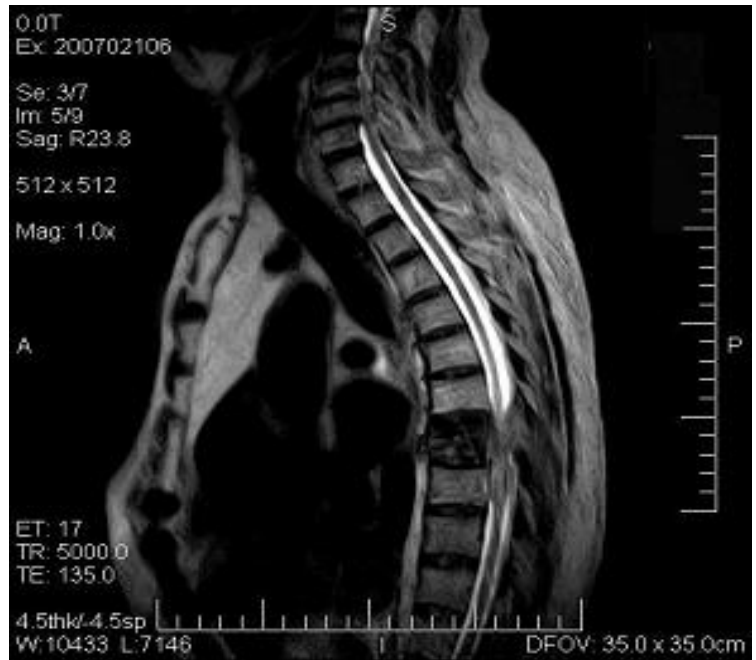

Image 4: $\mathrm{T}_{2}$ Sag Sclerotic Metastasis - Carcinoma Prostate

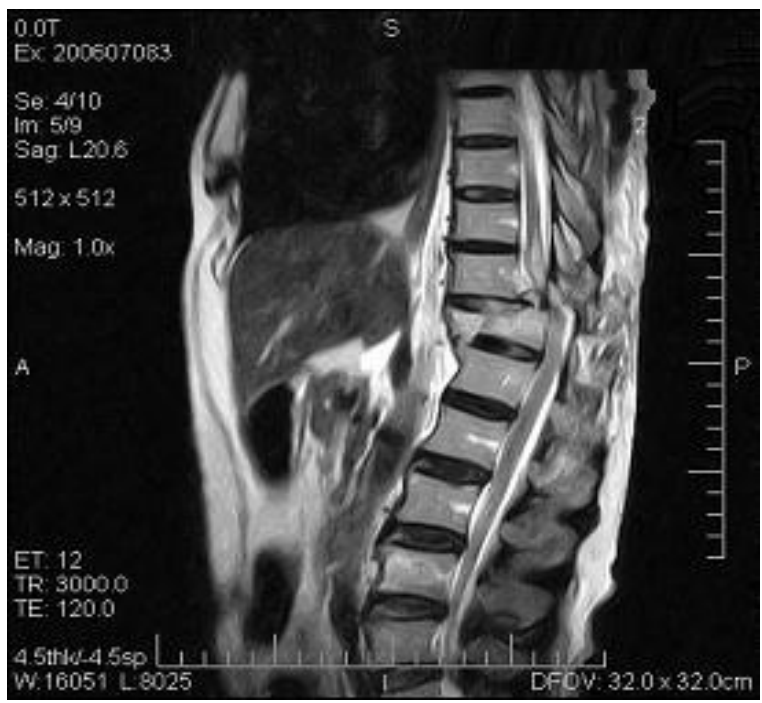

Image 5: Fracture Dislocation Causing Cord Edema Cord Compression

\section{Discussion}

A total of 60 patients referred were studied for compressive myelopathy using MRI in department of Radiodiagnosis, Veer Surendra Sai Institute of Medical Sciences and Research, Burla.

In our study 60 cases of compressive myelopathy we found different causes of compression. Among these are trauma (26), infectious cause (14), primary neoplasm (10), secondary neoplasm (10). 
In traumatic cases level of injuries were thoracic (53.8\%), cervical (46\%), lumbar (15.4\%) this comparable with study conducted by Kerslake et $\mathrm{al}^{1}$.

The age of patients in our study range from 12 to 70 year, mean 42 year and 22 were male and 4 were female (male:female-11:2). This is in comparission with study done by Yamashita et $\mathrm{al}^{2}$. Among 26 cases of traumatic compressive myelopathy RTA (70\%), fall from height (30\%), which is similar to study conducted by Kulkarni et $\mathrm{al}^{3}$.

Among 26 patients 24 had cord changes and 2 had no changes. 24 patiets showed hypointensity on T1WI, and hyperintensity on T2WI and FLAIR suggestive of cord edema and contusion .The signal changes are in consistence with study done previously by Hackney et $\mathrm{al}^{4}$.

In our study infectious causes of compressive myelopathy were (14). 12 cases were in thoracic region and 2 in lumbar region. Epidural component compressing the cord was seen in all the 14 cases. Study done by Roos DEA et $\mathrm{al}^{5}$ showed thoracolumbar region is the most common affected site as in our study.

We had 10 cases of primary neoplasm, among which 4 were neurofibroma \& 6 cases were meningioma. All the primary neoplasm were intradural extra medullary.

We had 10 cases of secondary neoplasm, out of which 6 patients $(60 \%)$ showed more than 1 lesion,this is comparison to study done by Lien et al ${ }^{6}$.Among 10 patients, we had 3 patients with primary carcinoma bronchus, 2 had breast carcinoma, 2 had lymphoma, 1 had carcinoma of prostate , 1 had RCC \& 1 with unknown primary.

In our study compartmental distribution of pathology. Out of 60 patients, 50 showing extradural, 10 showing intradural extra medullary pathology.

\section{Conclusion}

MRI could successfully characterize the spinal tumour based on location into extradural/ intradural and assess the integrity of spinal cord, intervertebral discs and ligament after acute trauma. So in the end MRI is very definitive, sensitive, accurate, though costly but very specific, noninvasive, radiation free modality for evaluation of compressive myelopathy

\section{References}

1. Kerslake RW, Jaspan T, Worthington BS. Magnetic resonance Imaging of Spinal trauma: The British Journal of Radiology. 1991;64:386-402.

2. Yamashita Y, Takahashi M, Matsuno Y, Kojima R, Sakamoto Y, Oguni T, et al. Acute Spinal cord Injury. Magnetic resonance Imaging correlated with myelopahty: The British Journal of Radiology. 1991;64:201-209.

3. Kulkarni MV, Mc Ardle CB, KapanickyD,Miner M, Cotler HB, Lee KF, etal. Acute Spinal Cord Injury. MR Imaging at $1.5 \mathrm{~T}$ : Radiology. 1987; 164: 837-843.

4. Hackney DB, Asata R, Sci DM, Joseph PM, Carvlin MJ, McGrath JT, Grossman RI, et al. Hemorrhage and edema in Acute spinal cord compression. Demonstration by MR Imaging: Radiology. 1986; 161: 387-390.

5. Roos DEA, Persijn V, Meerten EL, Bloem JI. MRI of Tubercular spondylitis: AJR. 1986; 146: 79-82.

6. Lien HH, Blomlie V, Heimdal $\mathrm{K}$. Magnetic Resource Imaging of malignant extradural tumors with acute spinal cord compression: Acta Radiologica. 1990; 31:187-190. 